\title{
A História da Condessa Surda de Lovelace: Um Relato de Experiência de Ensino Híbrido e Assistivo de Programação
}

\author{
Márcia Gonçalves de Oliveira ${ }^{1}$, Ana Carla Leite ${ }^{1}$, Mônica Ferreira Silva ${ }^{1}$, \\ Carla Marques Bodart ${ }^{1}$, Gabriel Silva X. Nascimento ${ }^{3}$ \\ ${ }^{1}$ Centro de Referência em Formação e Educação a Distância (Cefor) \\ Instituto Federal do Espírito Santo (Ifes) - Vitória - ES \\ ${ }^{2}$ Instituto Federal de São Paulo (IFSP) - Registro - SP \\ marcia.oliveiradifes.edu.br
}

\begin{abstract}
The history of Lovelace Deaf Countess narrates the learning experience of a deaf student through face-to-face workshops before and during the execution of a Python distance-learning program designed for girls. The hereby report developed by a teacher, a tutor and a Libras interpreter shows the development of the deaf student through a hybrid teaching approach for Programming and SWOT analyzes of assistance for the deaf student along her program trajectory. The results show advancement, nevertheless, the Deaf Countess of Lovelace wrote down an open letter to the Digital Girls Community reporting her experience, difficulties and development in Programming what illustrates how the Digital Girls can collaborate to the inclusion of more deaf girls in computing careers.
\end{abstract}

Resumo. A História da Condessa Surda de Lovelace trata de um relato de experiência da aprendizagem de programação de uma estudante surda através de oficinas presenciais antes e durante a execução de um curso de programação Python a distância para meninas. $O$ relato realizado por uma professora, uma tutora e uma intérprete de Libras apresenta a experiência da estudante surda em uma abordagem híbrida de ensino de programação e as análises SWOT de assistência à estudante surda em sua trajetória de aprendizagem de programação. Os resultados apontam para progressos, mas a Condessa Surda de Lovelace apresenta uma carta aberta para as Meninas Digitais relatando sua experiência de dificuldades e progressos e apresentando um apelo às Meninas Digitais para compreenderem as necessidades da comunidade surda e desenvolverem mais ações de inclusão de meninas surdas nas carreiras de computação.

\section{Introdução}

A programação de computadores é um conhecimento considerado de difícil aprendizagem por muitos estudantes e professores de informática porque para ser aprendido coloca em operação diversas habilidades cognitivas como a compreensão, reflexão, sequenciação lógica, organização estrutural, abstração, análise e depuração. Por isso, as dificuldades de aprendizagem de programação bem como as tecnologias e metodologias desenvolvidas como apoio ao ensino de programação têm sido temáticas recorrentes na literatura acadêmica de Informática na Educação [Souza et al. 2016]. Além disso, a literatura têm 
chamado à atenção para as ações de inclusão no ensino de programação, entre as quais destacamos neste trabalho a inclusão de mulheres e de surdos.

No caso das mulheres, além das comuns dificuldades de aprendizagem de programação, existem as dificuldades de aceitação e de permanência em uma área de conhecimento que, por ter sido predominantemente masculina ao longo dos anos, ainda existem muitos preconceitos e resistências.

No caso de estudantes surdos, de acordo com [Oliveira et al. 2018a], o desafio é ainda maior, pois a aprendizagem é dificultada pelas limitações no domínio da segunda língua que impacta diretamente nas habilidades de interpretação textual, na compreensão do problema, na sequenciação lógica de algoritmos, na escrita e na depuração de programas, que são habilidades fundamentais no processo de programação.

Contemplando essas dificuldades de aprendizagem de programação quando se tratam mulheres e surdos, este artigo apresenta uma solução de ensino híbrido de programação desenvolvida a partir da análise da experiência de aprendizagem de uma estudante surda no curso a distância de programação Python chamado Moodle de Lovelace. Essa solução é composta por oficinas presenciais de nivelamento em programação, um curso a distância de programação Python essencial, ativa e prática [Oliveira et al. 2018b] e aulas presenciais de reforço em programação com tutoria individual e interpretação de Libras.

Ao acompanhar de perto as dificuldades que a estudante surda enfrentou ao longo do curso de programação, entendemos que a principal contribuição deste trabalho para a aprendizagem de programação por estudantes surdos é oferecer uma solução de ensino híbrido e assistivo que possibilita um maior tempo e melhor assistência a estudantes surdos ao longo de um curso de programação. Mas, além de propor essa solução, a professora e sua equipe apresentam uma carta aberta da Condesssa Surda de Lovelace para as Meninas Digitais e fazem um apelo à comunidade das Meninas Digitais para que busquem compreender as necessidades da comunidade surda e desenvolvam mais ações para a inclusão de meninas surdas nas carreiras de computação.

Para apresentar o relato de experiência de ensino híbrido e assistivo de programação, este trabalho está organizado conforme a ordem a seguir. Na Seção 2, destacamos algumas ações desenvolvidas para o ensino de programação direcionado para surdos. $\mathrm{Na}$ Seção 3, relatamos uma experiência de ensino de programação para uma estudante surda, a quem chamamos de Condessa Surda de Lovelace. Na Seção 4, realizamos a análise SWOT da experiência de curso híbrido com a estudante surda. Na Seção 5, manifestamos uma carta aberta da Condessa Surda de Lovelace para as Meninas Digitais relatando-lhes a sua experiência e fazendo um apelo para inclusão de mais meninas surdas na computação. Na Seção 6, concluimos com as considerações finais.

\section{O ensino de programação para surdos}

$\mathrm{Na}$ área de ensino de informática, em especial de programação, ainda há uma carência de ações que promovam a inclusão de surdos [Oliveira et al. 2018a]. Na Tabela 1, apresentamos algumas dessas ações e, a partir delas, apontamos como as principais ações a serem realizadas na área de programação para promover a inclusão de surdos: compreender as limitações dos surdos para vencer os desafios de comunicação impostos pela linguagem falada, escrita e programada; capacitar professores e intérpretes para o trabalho colabora- 
tivo; desenvolver materiais adaptáveis e mais visuais; e desenvolver tecnologias assistivas que potencializem e facilitem a aprendizagem de programação dos estudantes surdos.

Faz-se necessário, portanto, ao considerar essas ações, pensar em metodologias de ensino que perpassem a questão visual dos surdos estimulando o pensamento lógico através da Libras e respeitando suas estruturas de organização semântica e sintática em softwares de programação. A partir daí, apresentam-se novos caminhos para promover o ensino da programação de um modo mais intuitivo que independa do esforço contínuo dos surdos em traduzir primeiro as proposições para então aplicá-las na resolução dos problemas [Oliveira et al. 2018a].

Tabela 1. Ações para inclusão de surdos na programação

\begin{tabular}{|l|l|}
\hline \hline Referências & Ações \\
\hline [Santos et al. 2011] & Desenvolvimento de um Dicionário Bilíngue em português e Libras. \\
\hline [Boscarioli et al. 2015] & $\begin{array}{l}\text { Treinamento de intérpretes para lidar com situações que ultrapassam a interpretação de sinais já existentes, atuando na criação de } \\
\text { sinais específicos que enriquecem o portfólio de sinais }\end{array}$ \\
\hline [Souza Santos et al. 2013] & $\begin{array}{l}\text { Concepção, construção, avaliação e validação de uma linguagem de programação para o estudo de lógica de programação por } \\
\text { deficientes auditivos, apoiado por uma IDE projetada para dar suporte às atividades, por intermédio de um intérprete virtual. }\end{array}$ \\
\hline [Santos et al. 2014] & $\begin{array}{l}\text { Desenvolvimento de um ambiente de edição de textos com foco no auxílio a estudantes com deficiência auditiva. Estudam-se } \\
\text { também formas de integrar a ferramenta com ambientes de redes sociais como o Twitter. }\end{array}$ \\
\hline [Gonçalves et al. 2015] & $\begin{array}{l}\text { Produção de Videoaulas de Programação em Java Acessíveis no Contexto de um Projeto de Capacitação Profissional para Pessoas } \\
\text { surdas em três etapas: elaborar conteúdo didático para gravação, produzir videoaula e gerar versão de produção. }\end{array}$ \\
\hline [Abuzinadah 2017] & $\begin{array}{l}\text { Avaliação da capacidade dos estudantes surdos para estudar e compreender um assunto altamente técnico como a programação de } \\
\text { computadores e a ação de desafiar a percepção generalizada de que o surdo não pode aprender assuntos complexos. }\end{array}$ \\
\hline [Oliveira et al. 2018a] & Neste trabalho vídeos assitivos de aulas de programação presenciais são produzidos para curso de programação a distância. \\
\hline
\end{tabular}

No trabalho mais recente sobre ensino de programação para surdos apresentado na Tabela 1 [Oliveira et al. 2018a], são informadas ações e tecnologias assistivas para o ensino de programação com a inclusão de estudantes surdos. A partir desse estudo, os principais desafios da inclusão de surdos na programação foram evidenciados, ações e tecnologias foram recomendadas e propôs-se um curso de programação estendido da modalidade presencial para a modalidade a distância através da geração de vídeos assistivos.

Neste trabalho, porém, considerando as dificuldades vivenciadas por uma estudante surda ao passar para o curso a distância de programação Moodle de Lovelace, propomos uma evolução desse curso para a modalidade híbrida que reúne oficinas de nivelamento de programação, o curso a distância e aulas de reforço com interpretação em Libras. Na seção a seguir, apresentamos uma experiência de aplicação dessa modalidade com a participação da estudante surda.

\section{Um relato de ensino hibrido e assistivo de programação}

O relato de ensino híbrido e assistivo apresentado nesta seção narra a trajetória de aprendizagem de uma estudante surda em um curso de programação Python a distância com oficinas presenciais de nivelamento e de atendimento a estudantes com dificuldades.

Essa estudante surda, a quem chamamos neste artigo de Condessa Surda de Lovelace, obteve o título simbólico de Condessa de Lovelace como emblema pelos seus progressos nas atividades do curso Moodle de Lovelace, conforme Figura 1. As primeiras aulas dela começaram no início do ano de 2018 junto com a primeira oferta do Moodle de Lovelace. Nessa oportunidade foram ministradas seis oficinas presenciais de nivelamento para duas estudantes surdas, sendo uma delas a própria Condessa Surda de Lovelace.

A professora de programação e as tutoras do curso a distância de programação Moodle de Lovelace, por não terem sequer o conhecimento básico da linguagem de sinais 


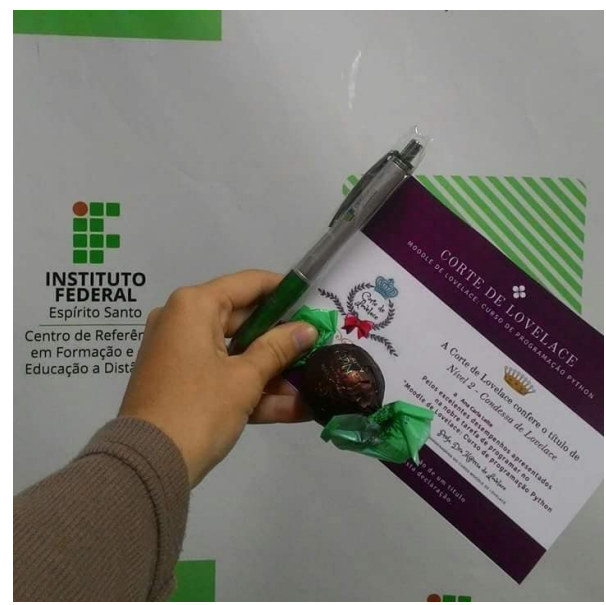

Figura 1. Título simbólico de Condessa de Lovelace do Grupo Corte de Lovelace

Libras, sentiram-se muito desafiadas a iniciar um curso de programação com a inclusão de surdos. Estas, embora tivessem o apoio de um intérprete de Libras que tinha conhecimentos básicos de programação, desconhecendo como os surdos aprendem, questionavam-se apreensivas como ensinariam programação para surdos.

A professora e as tutoras enfim decidiram abraçar o desafio de ensinar programação começando com duas estudantes surdas. Uma delas, porém, desistiu do curso após as duas primeiras aulas por conflitos de horários. Assim, apenas a Condessa Surda de Lovelace manteve a participação nas oficinas de nivelamento em programação.

As oficinas de nivelamento consistiram em aproximar a condessa surda da programação Python a partir do desenvolvimento do pensamento computacional e das habilidades envolvidas na prática da programação para diagnosticar possíveis lacunas na sua compreensão para resolver problemas do mundo real por programação. Dessa forma, trabalhamos nessas oficinas a compreensão de problemas por identificação de entrada processamento e saída, o desenvolvimento de sequências lógicas, uma introdução a variáveis, a lógica matemática, a construção de expressões lógicas, as estruturas condicionais e estruturas de repetição [Oliveira et al. 2018a]. Em seguida, iniciamos o desenvolvimento de algoritmos e da tradução destes em Linguagem Python.

Já na primeira aula das oficinas, reconhecemos os desafios de ensinar programação para as duas estudantes surdas. Em um considerável tempo da aula, as surdas tentavam entender o significado do sinal "+" e tentavam se ajudar na compreensão de uma simples instrução de operação aritmética de soma de dois números. A tutora questionou a si mesma "como ensinar programação se elas não compreendem as quatro operações básicas da matemática". Assim, a professora mudou toda a programação inicial das oficinas para ajudar as surdas nessa aproximação inicial com a programação e reorientou o curso para o desenvolvimento das habilidades de programação [Oliveira et al. 2018a].

O diferencial dessas oficinas que ajudou a condessa surda na compreensão da programação foi a utilização de exemplos do mundo real para desenvolver os conteúdos. Alguns desses exemplos são os seguintes: caixa de supermercados, urna eleitoral e sistemas de acesso com login e senha. Dessa forma, como bem afirmou a condessa, com esses exemplos, as construções de programação começaram a fazer sentido para ela. 


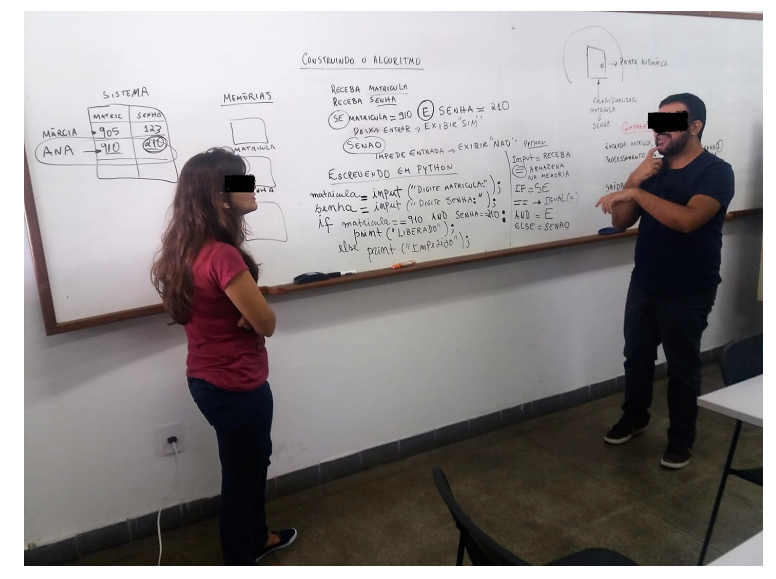

Figura 2. Oficina de Nivelamento em Programação - Estruturas Condicionais

Ao terminar a sexta oficina, a Condessa Surda de Lovelace externou o desejo de continuar aprendendo programação e de participar do curso de programação a distância Moodle de Lovelace, porém não foi possível a inserção dela na turma vigente do curso pois o mesmo já estava em andamento, o que nos levou a utilizar o conteúdo da sala como uma espécie de preparatório para ela ser inserida na próxima oferta do curso. No entanto, pelos progressos alcançados, no encontro presencial desse curso a distância, a estudante recebeu com honras da Corte de Lovelace o título de Condessa de Lovelace, emblema concedido (Figura 1) para quem alcança bons resultados em iniciação à programação.

O edital da segunda oferta do curso a distância de programação Python do Moodle de Lovelace reservou $10 \%$ das vagas para pessoas portadoras de deficiências (PCD). A Condessa Surda de Lovelace participou desse edital e foi aceita como aluna do curso a distância de programação.

A princípio, a professora do curso de programação a distância entendeu que, sendo a estudante surda bilíngue, ela conseguiria ler os arquivos das aulas, participar das atividades e interagir nos fóruns. Dessa forma, a professora iniciou o curso mesmo sem as adaptações dos materiais para Libras.

No entanto, logo na primeira semana do curso, a condessa surda teve muitas dificuldades com o material porque a língua portuguesa é uma segunda língua para ela, mas não é a mais cômoda para ela aprender os conteúdos, em especial os de programação que são mais complexos e envolvem uma linguagem de programação. Dessa forma, lidar com duas linguagens diferentes da sua linguagem própria, que é a Linguagem de Libras, foi extremamente difícil para a Condessa Surda de Lovelace.

Mas a condessa não desistiu de aprender programação e insistiu nos estudos solicitando às professoras da instituição ofertante do curso a distância aulas presenciais de assistência. Prontamente, a instituição disponibilizou uma intérprete de Libras, que logo se tornou também uma Menina Digital do grupo Corte de Lovelace.

A partir da solicitação da condessa surda, ficou decidido que ela continuaria as aulas presenciais, mas agora com a assistência de uma tutora e de uma intérprete de Libras ajudando-a nos conteúdos e atividades do curso a distância de Python. Já a professora do curso gravou uma aula de programação em Libras com a participação presencial da 
condessa surda. Além disso, a professora produziu em vídeo junto com a intérprete de Libras e mais duas aulas de programação com exercícios resolvidos de programação envolvendo expressões lógicas, estruturas de controle condicional e estruturas de controle de repetição. Esses vídeos foram disponibilizados no curso a distância como materiais assistivos de programação, mas precisam melhorar um pouco na qualidade audiovisual.

Com o atendimento presencial da tutora do curso de programação a distância e com o apoio da intérprete em Libras, a Condessa Surda de Lovelace vai superando os desafios de aprender programação, dedicando-se com muito entusiasmo a resolver os exercícios de Python, apresentando suas dúvidas e até solicitando mais exercícios para desenvolvimento da sua prática da programação.

Em aula presencial mais recente, a Condessa Surda de Lovelace apresentou e explicou à professora a análise de sua própria trajetória de aprendizagem de programação (Seção 4) no modelo de análise SWOT e entregou a Carta Aberta que escreveu para as Meninas Digitais, que é apresentada na Seção 5. Nessa carta, a condessa expõe sua experiência de dificuldades e progressos e faz um apelo à comunidade das Meninas Digitais para que mais ações de inclusão de meninas surdas sejam desenvolvidas.

\section{Análises SWOT de experiência em curso híbrido de programação}

Após a realização das oficinas presenciais e durante as últimas semanas do curso de programação Python a distância a professora, a tutora, a intérprete de Libras e a Condessa Surda de Lovelace realizaram uma avaliação diagnóstica da experiência delas no Modelo de Ensino Híbrido do curso de Programação Python do Moodle de Lovelace apresentado neste artigo através de matrizes de análise SWOT [Fernandes et al. 2015].

As tabelas 2, 3 e 4 apresentam as análises SWOT da equipe de acompanhamento da estudante surda no curso de programação.

Tabela 2. Análises SWOT - Professora e Tutora de Programação

\begin{tabular}{|c|c|c|c|}
\hline \multicolumn{4}{|c|}{ 車 } \\
\hline \multicolumn{2}{|c|}{ Análise SWOT - Professora de Programação } & \multicolumn{2}{|c|}{ Análise SWOT - Tutora de Programação } \\
\hline Pontos Fortes & Pontos Fracos & Pontos Fortes & Pontos Fracos \\
\hline $\begin{array}{l}\text { - Muita força de vontade da aluna } \\
\text { surda em aprender programação } \\
\text { mesmo com tantas dificuldades } \\
\text { - Facilidade no desenvolvimento de } \\
\text { metodologias para facilitar a } \\
\text { aprendizagem de programação } \\
\text { - Disponibilização de intérpretes pela } \\
\text { instituição que oferta o curso a distância } \\
\text { - Estrutura de EaD da instituição } \\
\text { - Oficinas de nivelamento }\end{array}$ & $\begin{array}{l}\text { - Não saber Libras } \\
\text { - Saber pouco sobre a } \\
\text { comunidade surda } \\
\text { - } \quad \text { Dificuldades para } \\
\text { produzir material assistivo } \\
\text { de melhor qualidade }\end{array}$ & $\begin{array}{l}\text { - Dedicação da estudante surda } \\
\text { - Dedicação da professora em preparar } \\
\text { um conteúdo adaptado para as aulas de } \\
\text { atendimento presenciais por mim } \\
\text { - Conteúdo das aulas sendo construído a } \\
\text { partir das necessidades específicas da } \\
\text { estudante surda. } \\
\text { - Adaptação do conteúdo já existente no } \\
\text { curso para uma melhor aprendizagem. }\end{array}$ & $\begin{array}{l}\text { - Disponibilidade de } \\
\text { equipamentos para a } \\
\text { ministração das aulas. } \\
\text { - Disponibilidade de } \\
\text { intérpretes para fazer o } \\
\text { revezamento na tradução } \\
\text { das aulas. } \\
\text { - Disponibilidade de } \\
\text { horário do interprete }\end{array}$ \\
\hline Oportunidades & Ameaças & Oportunidades & Ameaças \\
\hline $\begin{array}{l}\text { - Sensibilizar as Meninas Digitais para } \\
\text { desenvolvimento de soluções para } \\
\text { inclusão de meninas surdas na } \\
\text { computação } \\
\text { - Ampliar a oferta de vagas para surdos } \\
\text { em uma modalidade híbrida de ensino } \\
\text { de programação. } \\
\text { - Criar adaptações para surdos no } \\
\text { curso a distância de programação }\end{array}$ & $\begin{array}{l}\text { - Evasão, se não houver } \\
\text { acompanhamento } \\
\text { presencial. } \\
\text { - Tutoria voluntária, que } \\
\text { pode ser perdida ao longo } \\
\text { do curso }\end{array}$ & $\begin{array}{l}\text { - Aprendizado diário com la estudante } \\
\text { surda, pois ela é dedicada e se esforça o } \\
\text { máximo que pode dentro de sua limitação } \\
\text { para aprender e da forma dela tenta me } \\
\text { passar suas dúvidas para que eu possa } \\
\text { ajudá-la nas resoluções dos exercícios. }\end{array}$ & $\begin{array}{l}\text { - Minha falta de } \\
\text { conhecimento em Libras. } \\
\text { - Falta de políticas de } \\
\text { acessibilidade mais } \\
\text { contundentes. }\end{array}$ \\
\hline
\end{tabular}

A partir das análises SWOT, houve inicialmente uma conversa com a estudante surda para que ela explicasse suas análises e apontasse soluções. Dessa forma, com as 
Tabela 3. Análise SWOT - Intérprete de LIBRAS

\begin{tabular}{|l|l|}
\hline \multicolumn{1}{|c|}{ Pontos Fortes } & \multicolumn{1}{c|}{ Pontos Fracos } \\
\hline $\begin{array}{l}\text { - Auxílio da professora e da tutora em } \\
\text { esclarecer as noções básicas de } \\
\text { programação. } \\
\text { Compreensão clara do conteúdo por } \\
\text { parte da aluna surda. }\end{array}$ & $\begin{array}{l}\text { - Falta de conhecimento na área de } \\
\text { programação. } \\
\text { • Falta de conhecimento de terminologia } \\
\text { (signos em Libras) de sinais da área de } \\
\text { programação. }\end{array}$ \\
\hline \multicolumn{1}{|c|}{ Oportunidades } & \multicolumn{1}{c|}{ Ameaças } \\
\hline $\begin{array}{l}\text { - Descoberta dos principais conceitos e } \\
\text { nomenclaturas em Libras para a área de } \\
\text { programação estudada no curso. }\end{array}$ & Não há \\
\hline
\end{tabular}

Tabela 4. Análise SWOT - Estudante Surda

\begin{tabular}{|c|c|}
\hline Pontos Fortes & Pontos Fracos \\
\hline $\begin{array}{l}\text { - As professoras e intérprete de } \\
\text { - } \text { Libras foram ótimas no apoio } \\
\text { - Contato presencial e visual deu } \\
\text { para familiarizar-se e conseguir } \\
\text { desenvolver no curso. } \\
\text { - Ótima troca de interação } \\
\text { - Aulas de reforço presenciais } \\
\text { - Paciência das professoras } \\
\text { - Exercícios resolvidos similares } \\
\text { apresentados pela professora }\end{array}$ & $\begin{array}{l}\text { - Textos em Português podem atrapalhar a } \\
\text { compreensão e por vezes torna impossível que } \\
\text { responder de modo autônomo, no caso } \\
\text { dependeria de uma tradução. } \\
\text { - o ensino a distância é positivo, no entanto } \\
\text { ainda não está totalmente familiarizada com os } \\
\text { processos de interação no ambiente virtual. } \\
\text { - Dificuldades no acesso ao computador fora } \\
\text { da aula } \\
\text { - À distância, o tempo é pouco para resolver } \\
\text { as atividades } \\
\text { - Limitação em tirar dúvidas pelo Whatsapp }\end{array}$ \\
\hline Oportunidades & Ameaças \\
\hline $\begin{array}{l}\text { - Aprender de forma melhor a } \\
\text { programação } \\
\text { - Apoio do material didático } \\
\text { - Oficinas presenciais do curso a } \\
\text { distância ajudam a aprofundar os } \\
\text { conteúdos } \\
\text { - Acesso à biblioteca virtual e física } \\
\text { como aluna do curso }\end{array}$ & $\begin{array}{l}\text { - Língua portuguesa } \\
\text { - Linguagem de programação em inglês } \\
\text { - Prazo das atividades. O aluno surdo precisa } \\
\text { de mais tempo. } \\
\text { - Apenas EaD dificulta para o surdo. }\end{array}$ \\
\hline
\end{tabular}

análises SWOT da professora, da tutora e da intérprete, e considerando o esforço da condessa surda para aprender programação, decidiu-se por um replanejamento do curso com adaptações dos materiais, pelo menos os enunciados, e com soluções de exercícios resolvidos em Libras. Além disso, as oficinas presenciais de nivelamento e atendimento serão agregadas ao curso a distância Moodle de Lovelace, migrando, assim, para o modelo híbrido de ensino de programação.

\section{Carta aberta para as Meninas Digitais}

Com o objetivo de informar a comunidade das Meninas Digitais da Sociedade Brasileira de Computação sobre as dificuldades de aprendizagem de programação por estudantes surdos, a Condessa Surda de Lovelace, chamada de Ana Carla, escreveu uma carta aberta para as Meninas Digitais relatando a sua experiência de aprendizagem de programação, apontando os desafios que os surdos enfrentam na compreensão da programação, primeiro porque já têm dificuldades de interpretação na Língua Portuguesa e segundo porque aprendem uma Linguagem de Programação em Língua Inglesa.

De acordo com a Condessa Ana Carla, é muito complicado para o surdo compreender um problema a ser resolvido em Língua Portuguesa e gerar a solução desse problema em uma linguagem de programação que, em geral, é em Língua Inglesa, mesmo 
tendo já passado por oficinas de nivelamento de programação utilizando o Portugol ${ }^{1}$. As barreiras enfrentadas pela Linguagem demandam, portanto, um tempo maior de aprendizagem para estudantes surdos do que para ouvintes. Chamando a atenção das Meninas Digitais para essa questão, a Condessa Surda apresenta a seguinte carta aberta (com explicações de um intérprete de Libras e professor de Linguística):

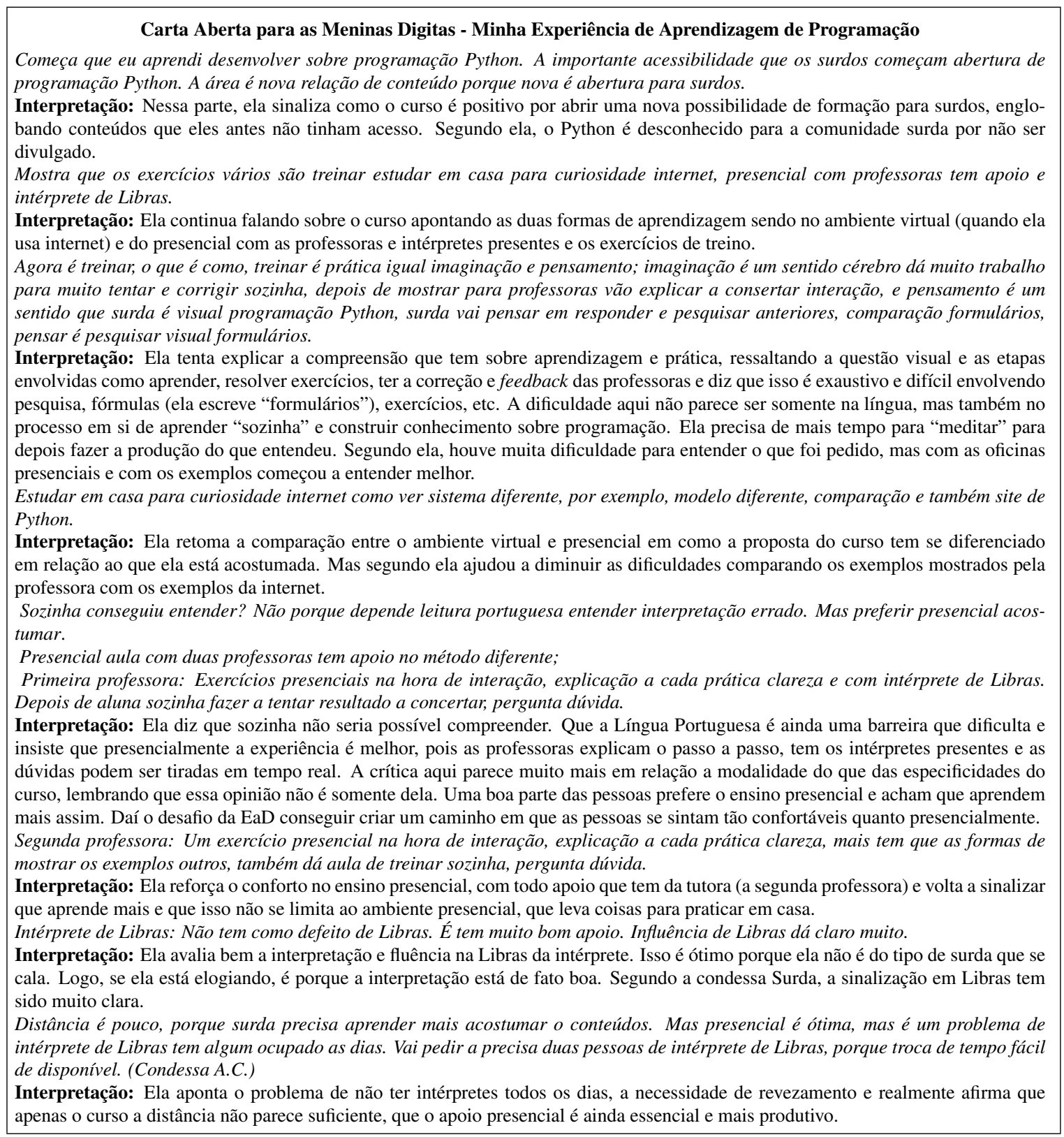

O intérprete de Libras da Carta Aberta finaliza destacando que os textos dessa carta não se tratam de erros comuns na escrita da língua portuguesa e sim marcas de uma falante de português como segunda língua. Além disso, o conceito de Pidgin ou língua de contacto é comum nas produções textuais de surdos.

Após ler a carta da Condessa surda de Lovelace e compreendê-la a partir das explicações de um intérprete, a professora ficou impressionada e comovida com o depoimento da condessa. Para a professora de programação, que não sabe Libras, os fatos de a estu-

\footnotetext{
${ }^{1}$ Pseudolinguagem de programação que é mais próxima da Língua Portuguesa
} 
dante ser bilíngue e a EaD ampliar as possibilidades de aprendizagem dos surdos através das tecnologias faziam-na acreditar que a EaD era suficiente para favorecer a aprendizagem de estudantes surdos. Mas para a Condessa Surda, só a EaD não era suficiente e era necessário ter o atendimento presencial também. Além disso, surpreendeu a professora como as dificuldades de aprendizagem de programação, tão comuns para outros estudantes, eram sobremaneira ampliadas para os surdos por causa das dificuldades com a Língua Portuguesa que se estendiam na língua inglesa e na Linguagem de Programação.

Considerando essas dificuldades, a professora decidiu migrar o curso a distância de programação Moodle de Lovelace para a modalidade híbrida.

Após receber as explicações da carta escrita pela própria Condessa Surda de Lovelace, a professora perguntou a ela, via intérprete, o que gostaria de pedir às Meninas Digitais para que mais meninas surdas pudessem ter a oportunidade de também aprender programação. A condessa sinalizou à professora que as pessoas da computação devem buscar compreender a comunidade surda e, como os surdos gastam mais tempo para compreender e acostumar com a programação, é importante que haja mais exercícios para acostumar com a Linguagem Python.

A condessa surda faz, portanto, um apelo, que é reforçado pela equipe da Corte de Lovelace, solicitando que, assim como ela se dispôs a compreender a Língua Portuguesa para aprender programação, as meninas e as professoras se disponham a aprender a linguagem de sinais dos surdos para que todos falem e compreendam Python.

\section{Considerações finais}

Este trabalho apresentou um relato de experiência de ensino híbrido e assistivo de programação para uma estudante surda através de oficinas presenciais de nivelamento, um curso de programação Python a distância e aulas presenciais de reforço.

Antes dessa experiência, o curso Moodle de Lovelace era ofertado somente a distância e a equipe acreditava que surdos bilíngues, apoiados por tecnologias, aprenderiam normalmente programação em um curso a distância. No entanto, o relato da Condessa Surda de Lovelace evidenciou que o curso deveria oferecer também um acompanhamento presencial para surdos e que estes precisam de tempo maior para responder às atividades propostas porque enfrentam as barreiras de compreensão da Língua Portuguesa.

Os desafios vivenciados pela estudante surda em lidar com três linguagens (Libras, Português e Python) contribuiram para que o Moodle de Lovelace passasse por adaptações e se aplicassem novas metodologias de ensino para inclusão de surdos. Dessa forma, as primeiras decisões tomadas foram oferecer um ensino híbrido de programação, promover adaptações para Libras nos materiais e promover ações de mobilização como, por exemplo, a Carta Aberta da Condessa Surda de Lovelace para as Meninas Digitais.

Concluindo, em seu depoimento apresentado à professora do curso, a Condessa Surda de Lovelace expressou em Libras que o Python está "escondido" para os surdos e os surdos estão "escondidos" para o Python, uma vez que há poucas ações para inclusão de surdos na programação. Atentando para essa afirmação e presenciando o esforço dessa estudante surda para aprender programação e enfrentar as próprias limitações, os autores desse artigo consideraram muito digno levar o apelo da comunidade surda para a comunidade das Meninas Digitais com a finalidade de incentivar mais ações de inclusão e ajudar 
mais meninas surdas a aprenderem programação.

\section{Agradecimentos}

Agradecemos ao Instituto Autoglass pelo apoio concedido às meninas do projeto Corte de Lovelace para a apresentação deste trabalho. Agradecemos também ao Cefor, espaço-sede da Corte de Lovelace no Ifes, pela cessão de seus professores, tutores, alunos, intérpretes de Libras e espaços presenciais e virtuais para a realização deste trabalho.

\section{Referências}

Abuzinadah, Nihal Esam; Malibari, A. A. K. P. (2017). Towards empowering hearing impaired students' skills in computing and technology. International Journal of Advanced Computer Science and Applications (IJACSA), 8(1).

Boscarioli, C., Galante, G., Oyamada, M. S., Zara, R. A., and Villwock, R. (2015). Aluno surdo na ciência da computação: Discutindo os desafios da inclusão. In XXIII Anais do Workshop de Informática na Escola (WEI) - CSBC 2015.

Fernandes, I. G. M., Figueiredo, H. M., da Costa Junior, H. L., Sanches, S. G., and Brasil, A. (2015). Planejamento estratégico: análise SWOT. Revista Conexão Eletrônica das Faculdades Integradas de Três Lagoas, Mato Grosso do Sul, 8(01).

Gonçalves, E., Vilela, J., Peixoto, M., Oliveira, F., and Castro, J. (2015). Produção de videoaulas de programação em java acessíveis no contexto de um projeto de capacitação profissional para pessoas surdas. In Brazilian Symposium on Computers in Education (Simpósio Brasileiro de Informática na Educação-SBIE), volume 26, page 877.

Oliveira, M., Nascimento, G., Lopes, M., Silva, A., da Costa, L. B., and Amaral, J. (2018a). Recomendações de ações e tecnologias para a acessibilidade de surdos em curso de programação a distância. In Anais do Workshop de Informática na Escola, volume 24 , page 459 .

Oliveira, M. G., Rutinelli da Penha, F., da Silva Lopes, M. F., Silva, A. C., do Amaral, J. G., Medeiros, H. F., et al. (2018b). O Moodle de Lovelace: Um Curso a Distância de Python Essencial, Ativo e Prático para Formação de Programadoras. In $12^{\circ}$ Women in Information Technology (WIT 2018). SBC.

Santos, R. E., Magalhães, C. V., Maciel, J., Correia-Neto, J. S., and Vilar, G. (2014). Informática na educação especial: uma discussão no contexto da educação de surdos. In Brazilian Symposium on Computers in Education (Simpósio Brasileiro de Informática na Educação-SBIE), volume 25, page 622.

Santos, R. E., Magalhães, C. V., Neto, J. S. C., and Júnior, S. S. P. (2011). Proglib: Uma linguagem de programação baseada na escrita de Libras. In Anais do Workshop de Informática na Escola, volume 1, pages 1533-1542.

Souza, D. M., da Silva Batista, M. H., and Barbosa, E. F. (2016). Problemas e dificuldades no ensino e na aprendizagem de programação: Um mapeamento sistemático. Revista Brasileira de Informática na Educação, 24(1).

Souza Santos, R. E., Magalhães, C. V., Correia-Neto, J. S., Queiros, L. M., and Vilar, G. (2013). Trabalhando lógica de programação com portadores de deficiência auditiva: a experiência com a linguagem Proglib e a IDE Hands. Revista Brasileira de Computação Aplicada, 6(1):32-44. 